\title{
A Randomized Double-Blind Parallel-Group Study to Evaluate the Long-Term Effects of a Medical Device Containing 0.3\% Octatrienoic Acid in the Treatment of Grade III Actinic Keratosis
}

\author{
Graziella Babino $\cdot$ Stefano Caccavale $\cdot$ Daniela Pinto $\cdot$ Anna Trink • \\ Giammaria Giuliani · Fabio Rinaldi (D) - Giuseppe Argenziano
}

Received: July 20, 2021 / Accepted: August 13, 2021 / Published online: September 2, 2021

(C) The Author(s) 2021

\begin{abstract}
Introduction: Actinic keratosis (AK) consists of skin lesions with a milder degree of keratinocytic atypia. It can be also referred to as "field of cancerization," which can potentially evolve to cutaneous squamous cell carcinoma (SCC). Several therapeutic options are currently available, but not all are indicated on hyperkeratotic lesions. This study aimed to test the efficacy and tolerability of a medical device containing 2,4,6-octatrienoic acid and urea for the treatment of hyperkeratotic AK lesions.

Methods: Seventy male and female subjects with grade III AK were enrolled in this randomized double-blind parallel-group study. The product was applied once daily for three consecutive months. The primary efficacy endpoint was the reduction in the mean number of $\mathrm{AK}$ lesions per subject from baseline (T0) to the end of the trial (T1) and 3 months after the end of the treatment period (T2). Therefore, clearance of target AK lesions at the end of the treatment period and local skin reaction score (LSR) versus baseline were evaluated.
\end{abstract}

G. Babino - S. Caccavale · G. Argenziano

Dermatology Unit, University of Campania Luigi

Vanvitelli, Naples, Italy

D. Pinto - A. Trink · G. Giuliani · F. Rinaldi $(\bowtie)$

Human Microbiome Advanced Project, HMAP,

Milan, Italy

e-mail: fabio.rinaldi@studiorinaldi.com
Results: There was a decrease of mean values from baseline to visit $\mathrm{T} 2$ in both treatment groups, but the decrease (versus baseline values) was more evident in the Kerà K2 group than in the placebo group $(-42.78, \mathrm{SD} 26.53$, versus -6.20 , SD 31.57), and the difference was statistically significant $(p<0.001)$. For 70 subjects $(56.7 \%)$ in the Kerà K2 group and $3(11.54 \%)$ in the placebo group, a significant $(p<0.005)$ partial clearance was evidenced. The product was well tolerated, and no serious adverse events were reported during the duration of the trial. Subject self-assessment of acceptability, local tolerability, and the cosmetic result was good at both T1 and T2 for both groups.

Conclusions: The medical device has demonstrated good efficacy in the reduction of visible AKs, encouraging its use.

Keywords: Hyperkeratotic actinic keratosis; 2,4,6-Octatrienoic acid; Urea; Topical treatment 


\section{Key Summary Points}

Why carry out this study?

Several therapeutic options are currently available, but not all are indicated on hyperkeratotic lesions.

Current guidelines recommend treating Actinic keratosis (AK), even if spontaneous lesion regression is possible to minimize the risk of progression to squamous cell carcinoma (SCC).

\section{What was learned from the study?}

Few clinical studies have addressed hyperkeratotic AKs. 2,4,6-Octatrienoic acid is reported to be effective on photodamaged skin and mild-tomoderate AKs.

In the present randomized double-blind parallel-group study, subjects with grade III AK were treated once daily for 3 months with the medical device under study showing a significant reduction in the number of AK lesions compared with placebo.

The total local skin reaction (LSR) scores were statistically reduced in subjects treated with the medical device after 3 months of treatment and follow-up (further 3 months). Complete clearance of lesions was observed during the first 3 months after the treatment period (i.e., the follow-up period) in $56.7 \%$ of the subjects treated with the medical device, and complete clearance was achieved in $27.5 \%$ of subjects during the first 3 months after the treatment period (i.e., the follow-up period).

\section{INTRODUCTION}

Actinic keratoses (AKs) are skin lesions with a milder degree of keratinocytic atypia confined to the lower epidermis part [1-5]. Actinic keratosis (AK) is reported by some authors as a precancerous lesion [2]; some others consider $\mathrm{AK}$ as an incipient form of squamous cell carcinoma (SCC) [6]. If referring to the histologically abnormal epithelium adjacent to tumor tissue, AKs can be also referred to as "field of cancerization," and this underlies the transformation of photodamaged skin into AKs and potentially cutaneous SCC $[7,8]$.

From a clinical point of view, AKs can be classified based on the degree of hyperkeratosis. The classification includes (1) grade I-flat, pink maculae without signs of hyperkeratosis and erythema often easier felt than seen, flat erythematous macules with or without scale and possible pigmentation; (2) grade II-moderately thick hyperkeratosis on a background of erythema that is easily felt and seen; (3) grade IIIvery thick hyperkeratosis, or obvious AK, differential diagnosis cutaneous horn [9].

AKs are common in elderly and middle-aged fair-skin people, appearing as rough, dry, scaly lesions occurring primarily on sun-exposed skin.

Although the exact mechanism of $\mathrm{AK}$ pathogenesis development remains unknown, ultraviolet (UV)-induced DNA damage is considered as the main factor responsible for the initiation of the precancerous process [10]. UV induces the formation of major dimer configurations by covalent bonds between two adjacent pyrimidines that interfere with biological processes (e.g., transcription and replication) critical for cell viability [11]. If left unrepaired, these lesions can induce mutations and progress into squamous cell carcinoma and, occasionally, metastatic tumor type. It is also believed that prolonged ultraviolet exposure changes the immune surveillance mechanism of the skin, contributing to the tolerance of tumor cells. Recent studies demonstrated that approximately $20-27 \%$ of cutaneous SCC arise in an AK [12] and approximately $10 \%$ of all AKs could progress to invasive SCCs in 2 years [13].

It is very difficult to predict which lesions could progress to SCC. Consequently, treatment of the cancerization field is recommended as a preventive measure to reduce actinic damage and the risk for neoplasm progression [14]. 
Several therapeutic options are currently available, both administered by qualified physicians and applied directly by patients. Standard treatments can be physical (cryotherapy, curettage, surgical excision, photodynamic therapy, and laser therapy) and topical (e.g., 5-fluorouracil, diclofenac, ingenol mebutate, imiquimod) [15]. Unfortunately, these treatments are often associated with scarring, pain, or inflammation, may not address subclinical lesions, and are not always satisfactory [16].

The medical device under study is a cream with keratolytic activity containing 15\% urea and $0.3 \% 2,4,6$-octatrienoic acid. Urea is widely used in dermatology to promote rehydration of the skin because of its keratolytic activity [17].

2,4,6-Octatrienoic acid possesses antioxidant, antiinflammatory activity $[18,19]$. It was demonstrated to have the ability to increase the biological antioxidant potential and the expression and activity of catalase [17]. Most interestingly, the activation of peroxisome proliferator-activated receptor gamma (PPAR $\gamma$ ) by 2,4,6-octatrienoic acid protects human keratinocytes from ultraviolet radiation (UVR)-induced damage [19].

In the present study, we evaluated the effectiveness of a new class II medical device (Kerà K2) for the treatment of grade III AK.

We carried out a double-blind, controlled, parallel study to evaluate the efficacy of Kerà K2 cream versus a placebo cream containing 15\% urea (henceforth called placebo) in patients applying once a day Kerà K2 to assess the efficacy and tolerability of this medical device in subjects with grade III AK.

\section{METHODS}

\section{Participants}

The study was performed in two dermatology clinics in Italy and was approved by the ethical committee of the University of Campania, Naples, Italy; written informed consent was requested and received from all subjects in the study. The study was carried out between September 2017 and January 2020.

Inclusion criteria were the following:
- grade $3 \mathrm{AKs}$, with $\geq 3$ lesions located in the same anatomical region (within a contiguous $50 \mathrm{~cm}^{2}$ area on the face, bold scalp, forehead, arms; the $50 \mathrm{~cm}^{2}$ area could be of any dimension, e.g., $7 \times 7 \mathrm{~cm}, 6 \times 8.3 \mathrm{~cm}$, $4 \times 12.5 \mathrm{~cm})$;

- female or male $>18$ years of age;

- skin type I to III according to Fitzpatrick;

- patient has confirmed his/her willingness to participate in this study.

- Exclusion criteria were the following:

- subjects suitable for surgical, photodynamic, or any other topical treatment in the next 6 months or with an early stage of skin cancer;

- other skin disease treated with other medications in the treatment zone or distance of $3 \mathrm{~cm}$;

- immunosuppression or treatments for cancer;

- clinically unstable medical state;

- high-risk group for infectious diseases [human immunodeficiency virus (HIV), hepatitis A, B, or C, tuberculosis, etc.];

- contact allergies or allergies to compounds of the test substances;

- psychiatric comorbidities that may interfere with follow-up of study procedures;

- prior treatment with study medication in the area to be treated.

A total of 70 subjects were enrolled.

\section{Treatment/Intervention}

The study consisted of a baseline visit (T0), one evaluation visit after 3 months of treatment (T1, day 90), and a final visit of follow-up after 3 months by the end of treatment (T2; day 180).

All subjects were instructed to self-apply the product, once daily, preferably in the evening, on the target $\mathrm{AK}$ lesions on a $50 \mathrm{~cm}^{2}$ contiguous treatment area (the area could be of any dimensions, e.g. $7 \times 7 \mathrm{~cm}, 6 \times 8.3 \mathrm{~cm}$, $4 \times 12.5 \mathrm{~cm}$ ); subjects were also advised to avoid sun exposure or to apply sunscreen.

The following procedures were carried out at the baseline visit (T0; day 0):

informed consent signed; 
- inclusion/exclusion criteria;

- demographic data and medical history;

- physical examination (phototype, history of sunburns, freckles);

- AK diagnosis: no. of areas affected by AK, localization of AK area, number and grade of AK present at baseline;

- Baseline Severity Index (BSI);

- photographic documentation;

- reflectance confocal microscopy (RCM) evaluation in the target area and the cancerization field.

Following medical history and verification of $\mathrm{AK}$, the subjects were randomized to one of the two treatment groups.

During follow-up visit T1, 3 months (90 days) after the first application of the cream, the following procedures were performed:

- local skin reaction score (LSR);

- photographic documentation;

- RCM evaluation in the target area and in the cancerization field;

- collection and monitoring of adverse events;

- subject self-assessment of acceptability, local tolerability, and cosmetic result.

During follow-up visit T2, 3 months after the end of the treatment (180 days after the first application of the cream), the following procedures were performed:

- AK diagnosis: localization of AK area, number, and grade of AKs;

- local skin reaction score (LSR);

- collection and monitoring of adverse events;

- subject self-assessment of acceptability, local tolerability, and cosmetic result.

\section{Primary Outcomes}

The primary efficacy endpoint was the percentage change, at the end of the treatment period, in the number of AK lesions that were originally defined in the selected AK target area at baseline.

The percentage change in the number of $\mathrm{AK}$ lesions was calculated as the number of lesions present at the end of the treatment period in the target area minus the number of AK lesions present in the target area at baseline visit divided by the number of lesions present in the target area at baseline.

\section{Secondary Outcomes}

The secondary efficacy analyses were the following: (1) percentage of subjects with partial clearance of AK lesions at the end of the treatment period (partial clearance being defined as a $50 \%$ reduction in the number of target AK lesions; (2) percentage of subjects with total clearance of target AK lesions at the end of the treatment period; (3) percentage of subjects with no AK lesion (cumulative number of lesions) at the end of the treatment period; (4) change from baseline in the Baseline Severity Index (BSI); (5) change from baseline in the target area clinical assessment; (6) clinical Investigator Global Improvement Indices (IGII) score; (7) subject's assessment of satisfaction to the product at the end of the treatment period; and (8) change from baseline in reflectance confocal microscopy (RCM) score of the target area and RCM score of cancerization field at the end of the treatment period. All patients performed a baseline RCM examination of the skin at the level of cancerization field, which included a typical AK lesion selected to define the target area and the perilesional area. RCM images of the areas selected at baseline were acquired using a laser scanning device (VivaScope 1500; Caliber I.D., Ronchester, NY, USA) that scans the skin horizontally from the epidermis up to the papillary dermis (diode laser, 830-nm laser beam with a maximum power of $35 \mathrm{~mW}$ ). A $4 \times 4 \mathrm{~mm}$ Vivacube composed of four mosaics at $25-\mu \mathrm{m}$ steps was collected at baseline and during the follow-up visit. Each RCM criteria was scored 0 (absent), 1 ( $<25 \%), 2$ (25-50\%), 3 (50-75\%), or 4(>75\%). Moreover, the extent of the criteria was evaluated by dividing the mosaic area into quarters $(<25 \%$ of the area; $25-50 \%$; 75\%; > 75\%).

\section{Ethics}

This study was conducted in compliance with the ethical principles originating in or derived 
from the Declaration of Helsinki and in compliance with Good Clinical Practice Guidelines and was approved by the ethical committee of the University of Campania, Naples, Italy. All subjects provided signed informed consent.

\section{Statistical Analysis and Sample Size}

Statistical analysis was performed using GraphPad statistical software version 13.0 (La Jolla, CA, USA). Continuous variables were expresses as mean \pm standard deviation (SD). The primary efficacy endpoint was the percentage change, at the end of the follow-up period (visit T2, day 180), in the number of AK lesions that were originally defined in the selected AK target area at baseline. This variable was analyzed using a non-parametric test (Wilcoxon ranksum test). The secondary endpoints concerning AK lesions were analyzed using Fisher's exact test; 95\% confidence interval for the betweengroup difference in percentages is provided. Change from baseline in the BSI, change from baseline in the target area clinical assessment, and change from baseline in RCM score of the target area and RCM score of cancerization field at the end of the treatment period were compared between the groups using a $t$ test; 95\% confidence interval for the between-group difference is provided.

The sample size was determined as a minimum of 30 evaluable subjects by treatment arm based on the hypothesis that the percentage reduction in the number of $\mathrm{AK}$ lesions in the Kerà K2 group would be at least 30\% larger than in the placebo arm at the end of the treatment period. Thirty subjects per group enable the detection of the above effect with power of $>90 \%$ and a significance level of 5\%. Therefore, the sample size calculation assumes that a maximum of $25 \%$ of enrolled subjects will drop out for various reasons during the study period.

\section{RESULTS}

Fifty-six of the enrolled subjects (86\%) completed the study (29 in the Kerà K2 group and 27 in the placebo group). Nine subjects were withdrawn before visit $\mathrm{T} 1$ and five between visit
Table 1 Subject's characteristics at baseline, and medical history

\begin{tabular}{lll}
\hline & $\begin{array}{l}\text { Kerà K2 } \\
(\boldsymbol{N}=\mathbf{3 6})\end{array}$ & $\begin{array}{l}\text { Placebo } \\
(\boldsymbol{N}=\mathbf{3 4})\end{array}$ \\
\hline Age (years) & & \\
No. pts. & 36 & 34 \\
Mean & 73.00 & 75.21 \\
SD & 6.96 & 6.14 \\
Sex & & \\
Male & $20(56.00 \%)$ & $21(59.6 \%)$ \\
Female & $16(44.00 \%)$ & $13(40.4 \%)$ \\
Family history of skin & & \\
cancer & & $25(73.5 \%)$ \\
No & $27(75.0 \%)$ & $7(20.6 \%)$ \\
Yes & $2(5.5 \%)$ & $2(5.9 \%)$ \\
Not specified & $7(19.4 \%)$ & $12(35.3 \%)$ \\
Previous skin cancer & & $22(64.7 \%)$ \\
No & $17(47.2 \%)$ & $20(58.8 \%)$ \\
Yes & $19(52.8 \%)$ & $14(41.2 \%)$ \\
Previous treatment for & & \\
AK & & \\
No & $14(38.8 \%)$ & $12.9 \%)$ \\
Yes & $22(61.2 \%)$ & \\
Other dermatologic & & \\
Rosacea & & \\
Psoriasis & & \\
None & & \\
Not specified & $25(69.4 \%)$ & $21(61.8 \%)$ \\
\hline
\end{tabular}

T1 and T2. Subjects' characteristics are presented in Table 1.

The studied pathology (AK) was reported by the subjects to be present in the last 20 years (data not shown). The most frequent treatments were cryotherapy and photodynamic therapy (PDT) in both treatment groups. 
Table 2 Physical examination at baseline

\begin{tabular}{lll}
\hline & $\begin{array}{l}\text { Kerà K2 }^{\circledR} \\
(\boldsymbol{N}=36)\end{array}$ & $\begin{array}{l}\text { Placebo } \\
(\boldsymbol{N}=\mathbf{3 4})\end{array}$ \\
\hline Phototype & & \\
I & $6(16.6 \%)$ & $5(14.7 \%)$ \\
II & $22(61.2 \%)$ & $23(67.6 \%)$ \\
III & $8(22.2 \%)$ & $6(17.7 \%)$ \\
History of sunburns & & \\
No & $30(83.3 \%)$ & $15(44.1 \%)$ \\
Yes & $6(16.7 \%)$ & $19(55.9 \%)$
\end{tabular}

Freckles

$\begin{array}{lll}\text { No } & 28(77.7 \%) & 28(82.3 \%) \\ \text { Yes } & 5(13.8 \%) & 4(11.8 \%) \\ \text { Not specified } & 3(8.4 \%) & 2(5.9 \%)\end{array}$

Number of areas affected by AK

1

2

3

Not specified

Location of AK

Check

Face

Front

Hand-forearm

Scalp

Number of AKs

$\begin{array}{lll}\text { Mean } & 6.61 & 6.61 \\ \text { SD } & 3.18 & 2.87\end{array}$

Grade of AK

\begin{tabular}{lll} 
I & $4(11.1 \%)$ & \\
I-II & $11(30.5 \%)$ & $13(38.2 \%)$ \\
II & $12(30.3 \%)$ & $9(26.5 \%)$ \\
II-III & $1(8.3 \%)$ & $7(20.6 \%)$ \\
III & $6(19.8 \%)$ & $5(14.7 \%)$ \\
\hline
\end{tabular}

Table 2 continued

\begin{tabular}{lll}
\hline & $\begin{array}{l}\text { Kerà K2 }^{\circledR} \\
(\boldsymbol{N}=\mathbf{3 6})\end{array}$ & $\begin{array}{l}\text { Placebo } \\
(\boldsymbol{N}=34)\end{array}$ \\
\hline BSI score & & \\
Mild & $8(22.2 \%)$ & $8(23.5 \%)$ \\
Moderate & $13(36.1 \%)$ & $16(47.1 \%)$ \\
Severe & $15(41.6 \%)$ & $10(29.4 \%)$ \\
\hline
\end{tabular}

Table 3 Number of AK lesions-percentage change at T2 versus baseline

\begin{tabular}{lrrl}
\hline & $\begin{array}{l}\text { Kerà } \\
\mathbf{K 2}^{\circledR} \\
(\boldsymbol{N}=\mathbf{3 0})\end{array}$ & $\begin{array}{l}\text { Placebo } \\
(\boldsymbol{N}=\mathbf{2 6})\end{array}$ & $\begin{array}{l}\text { Comparison } \\
\text { between } \\
\text { treatments } \\
\text { Wilcoxon rank- } \\
\text { sum test }(\boldsymbol{p} \text { value })\end{array}$ \\
\hline $\begin{array}{l}\text { Baseline } \\
\text { Mean }\end{array}$ & 5.53 & 4.96 & \\
SD & 2.40 & 2.75 & \\
Visit T2 (day & & & \\
180) & & & \\
Mean & 3.17 & 4.65 & \\
SD & 1.49 & 2.67 & \\
Visit T2- & & & \\
percentage & & & \\
change & & & \\
versus & & & \\
baseline & & & \\
Mean & -42.78 & -6.20 & $<0.001$ \\
SD & 26.53 & 31.57 & \\
\hline
\end{tabular}

The results concerning the physical examination at baseline are reported in Table 2 .

The mean values of the number of AK lesions reported at baseline and visit $\mathrm{T} 2$, and the changes of $\mathrm{T} 2$ versus baseline, are summarized in Table 3 for the two treatment groups. 


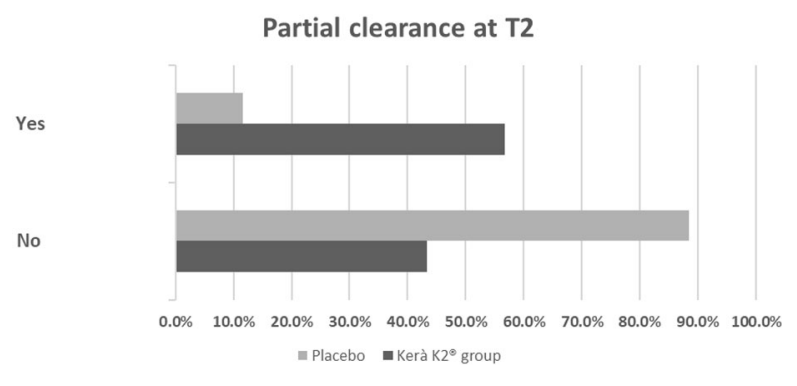

Fig. 1 Partial clearance at T2

Table 4 Local skin reaction score (LSR) - total score

\begin{tabular}{|c|c|c|c|}
\hline & $\begin{array}{l}\text { Kerà } \\
\mathrm{K}^{\circledR}{ }^{\circledR} \\
(N=30)\end{array}$ & $\begin{array}{l}\text { Placebo } \\
(N=26)\end{array}$ & $\begin{array}{l}\text { Comparison } \\
\text { between } \\
\text { treatments } \\
\text { Wilcoxon rank- } \\
\text { sum test ( } p \text { value) }\end{array}$ \\
\hline \multicolumn{4}{|c|}{$\begin{array}{l}\text { Visit T1 (day } \\
\text { 90) }\end{array}$} \\
\hline Mean & 3.39 & 10.50 & $<0.001$ \\
\hline SD & 2.05 & 5.81 & \\
\hline \multicolumn{4}{|c|}{$\begin{array}{l}\text { Visit T2 (day } \\
180)\end{array}$} \\
\hline Mean & 3.70 & 9.50 & \\
\hline SD & 2.32 & 5.76 & \\
\hline \multicolumn{4}{|c|}{$\begin{array}{l}\text { Visit T2- } \\
\text { percentage } \\
\text { change } \\
\text { versus } \\
\text { baseline }\end{array}$} \\
\hline Mean & -42.78 & -6.20 & $<0.001$ \\
\hline SD & 26.53 & 31.57 & \\
\hline
\end{tabular}

As shown, there was a decrease of mean values from baseline to visit $\mathrm{T} 2$ in both treatment groups, but the decrease (versus baseline values) was more evident in the Kerà $\mathrm{K} 2$ group with respect to the placebo group, -42.78 (SD 26.53) versus -6.20 (SD 31.57) and was statistically significant (Wilcoxon rank-sum test: $p<0.001)$.
Figure 1 shows the partial clearance (defined as a $50 \%$ reduction in the number of target $\mathrm{AK}$ baseline lesions) at visit T2. For 70 subjects (56.7\%) in the Kerà K2 group and 3 (11.54\%) in the placebo group, a partial clearance was evidenced. Statistically significant difference between treatments $\left(\chi^{2}\right.$ test: $\left.p<0.005\right)$.

Table 4 summarizes the mean values of total LSR scores at visits T1 and T2. At T1 (90 days), the total score was higher in the placebo group than in the Kerà $\mathrm{K} 2$ group $(3.39 \pm 2.05$ versus $10.50 \pm 5.81)$, and the difference between treatments was statistically significant (Wilcoxon rank-sum test: $p<0.001)$. This trend was confirmed at T2 (180 days) $(9.50 \pm 5.76$ versus $3.70 \pm 2.32$ ).

To detect morphological changes following treatment, RCM evaluations of AK were performed at baseline and at day 90 (T1) and day 180 (T2). Abnormal features and parakeratosis were observed in almost all at T0. The presence of scaling, hyperkeratosis, polygonal nucleated cells, atypical honeycomb, inflammatory cells, curled fibers, increased vascularity, and dermal inflammation significantly $(p<0.05)$ decreased since 90 days of treatment with Kerà K2 and these results increased after 180 days of treatment. RCM findings are summarized in Table 5, and an example of comparative RCM imaging is shown in Fig. 2.

Figure 3 shows one patient with an evident $\mathrm{AK}$ reduction, as representative of the entire Kerà K2 group.

The product was well tolerated. No serious adverse events were reported during the duration of the trial.

Subject self-assessment of acceptability, local tolerability, and the cosmetic result were good at both $\mathrm{T} 1$ and $\mathrm{T} 2$ for both groups.

\section{DISCUSSION}

Current guidelines recommend treating $\mathrm{AK}$, even if spontaneous lesion regression is possible to minimize the risk of progression to SCC [20]. Several treatment options are available, and they are categorized into lesion and field- 
Table 5 Evolution of RCM scores in patients receiving treatment with Kerà $\mathrm{K} 2$ and placebo

\begin{tabular}{|c|c|c|}
\hline & $\begin{array}{l}\text { Kerà K2 }{ }^{\circledR} \\
(N=30)\end{array}$ & $\begin{array}{l}\text { Placebo } \\
(N=26)\end{array}$ \\
\hline \multicolumn{3}{|l|}{ Visit T0 (day 0) } \\
\hline Scales & $23(76 \%)$ & $23(88 \%)$ \\
\hline Hyperkeratosis & $28(93 \%)$ & $20(77 \%)$ \\
\hline Polygonal KC & $23(77 \%)$ & $14(54 \%)$ \\
\hline $\begin{array}{l}\text { Atypical } \\
\text { honeycomb }\end{array}$ & $27(90 \%)$ & $25(96 \%)$ \\
\hline Inflammatory cells & $25(83 \%)$ & $19(73 \%)$ \\
\hline Curled fibers & $25(83 \%)$ & $23(88 \%)$ \\
\hline $\begin{array}{l}\text { Increased } \\
\text { vascularity }\end{array}$ & $21(70 \%)$ & $16(62 \%)$ \\
\hline $\begin{array}{l}\text { Dermal } \\
\text { inflammation }\end{array}$ & $24(80 \%)$ & $18(69 \%)$ \\
\hline \multicolumn{3}{|l|}{ Visit T1 (day 90) } \\
\hline Scales & $18(60 \%)$ & $21(81 \%)$ \\
\hline Hyperkeratosis & $17(57 \%)$ & $22(87 \%)$ \\
\hline Polygonal KC & $12(40 \%)$ & $24(92 \%)$ \\
\hline $\begin{array}{l}\text { Atypical } \\
\text { honeycomb }\end{array}$ & $13(43 \%)$ & $23(88 \%)$ \\
\hline Inflammatory cells & $11(37 \%)$ & $19(84 \%)$ \\
\hline Curled fibers & $9(30 \%)$ & $20(79 \%)$ \\
\hline $\begin{array}{l}\text { Increased } \\
\text { vascularity }\end{array}$ & $7(23 \%)$ & $16(62 \%)$ \\
\hline $\begin{array}{l}\text { Dermal } \\
\text { inflammation }\end{array}$ & $17(56 \%)$ & $22(85 \%)$ \\
\hline \multicolumn{3}{|l|}{ Visit T2 (day 180) } \\
\hline Scales & $6(20 \%)$ & $21(81 \%)$ \\
\hline Hyperkeratosis & $7(26 \%)$ & $22(87 \%)$ \\
\hline Polygonal KC & $5(17 \%)$ & $24(92 \%)$ \\
\hline $\begin{array}{l}\text { Atypical } \\
\text { honeycomb }\end{array}$ & $8(27 \%)$ & $23(88 \%)$ \\
\hline Inflammatory cells & $6(20 \%)$ & $19(84 \%)$ \\
\hline Curled fibers & $9(30 \%)$ & $20(79 \%)$ \\
\hline
\end{tabular}

Table 5 continued

\begin{tabular}{lll}
\hline & $\begin{array}{l}\text { Kerà K2 }^{\circledR} \\
(\boldsymbol{N}=\mathbf{3 0})\end{array}$ & $\begin{array}{l}\text { Placebo } \\
(\boldsymbol{N}=\mathbf{2 6})\end{array}$ \\
\hline $\begin{array}{l}\text { Increased } \\
\text { vascularity }\end{array}$ & $4(13 \%)$ & $16(62 \%)$ \\
$\begin{array}{l}\text { Dermal } \\
\text { inflammation }\end{array}$ & $9(30 \%)$ & $22(85 \%)$ \\
\hline
\end{tabular}

directed therapies. The choice of the best treatment must be made based on the number of AK lesions, their localization, the period after the first onset, subject age, treatment compliance, and comorbidities. Treatments will depend also on the forms of AK such as hyperkeratotic, atrophic, pigmented lichenoid, cutaneous horn, and actinic cheilitis [21].

All the available therapies are reported as effective, even if not all of the approved treatments (i.e., ingenol mebutate, imiquimod, and diclofenac) are indicated on hyperkeratotic lesions.

A study by Tan and collaborators [22] reported that up to $25 \%$ of AK lesions are hyperkeratotic, depending on the body area considered. Curettage and electrocoagulation are indicated as physical therapies for isolated or small numbers of hyperkeratotic, well-delimited, and nonsuspicious AKs [23]. Therefore, most AKs, including ones that are hyperkeratotic, can be well managed with topical treatments such as dermocosmetics, e.g., emollients, which can improve subject comfort by reducing skin dryness and roughness. For hyperkeratotic AKs, also the use of topical keratolytics containing urea or salicylic acid (SA) is suggested [23] for their ability to exfoliate the superficial layers of the epidermis cleavage of the corneodesmosomes. A more intense approach is suggested in immunosuppressed subjects and when AK lesions are present in particular body areas (nose, eyelids, ears, lips) [24]. Therefore, low-dose $0.5 \%$ 5-fluorouracil/SA [25] and topical imiquimod (5\% cream) [26] have been reported as effective and well-tolerated 
A

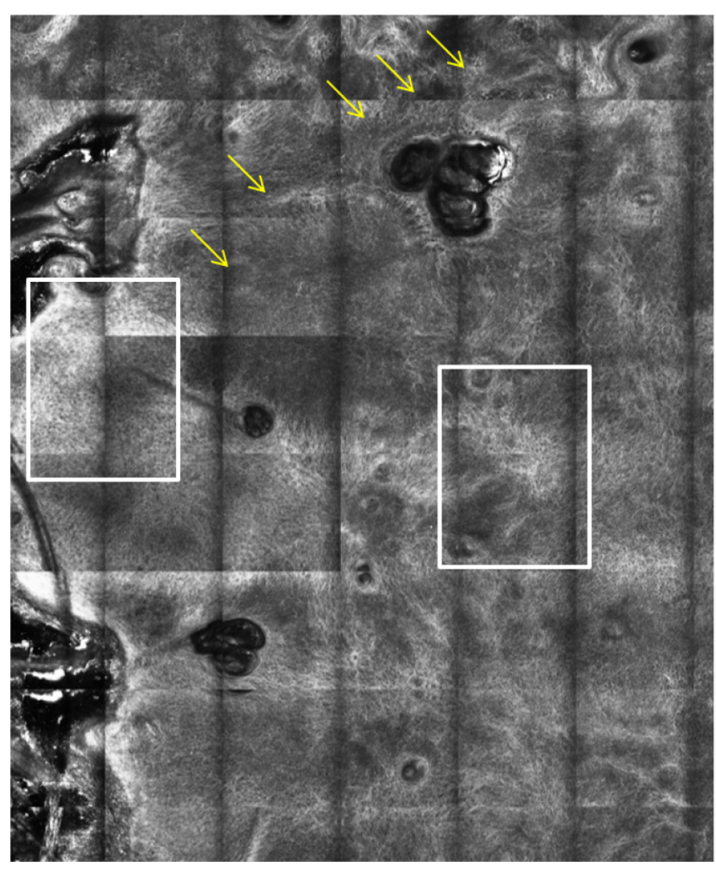

Fig. 2 RCM imaging at baseline (A) and after treatment (B). A Image of stratum corneum showing atypical honeycomb pattern (squares) with irregular keratinocytes in size and shape and lots of inflammatory cells (yellow

treatment of mild-to-moderate hyperkeratotic AK lesions.

Previous studies reported the efficacy of a product containing 2,4,6-octatrienoic acid for both the prevention and treatment of non-hyperkeratotic [27] and hyperkeratotic AKs [28].

Few clinical studies have addressed hyperkeratotic AKs. A study by De Padova and collaborators [26] reported that the combination of the parrodiene derivative 2,4,6-octatrienoic acid with urea is a safe and effective treatment for hyperkeratotic AKs.

2,4,6-Octatrienoic acid is reported to be effective on photodamaged skin and mild-tomoderate AKs $[18,19]$. As a parrodiene derivative, 2,4,6-octatrienoic acid possesses antioxidant and antiinflammatory activity and inhibits cell membrane lipoperoxidation $[29,30]$. It acts by PPAR- $\gamma$ activation, and this leads to the reduction of oxidative damage and inflammation and the induction of DNA repair mechanisms.
B

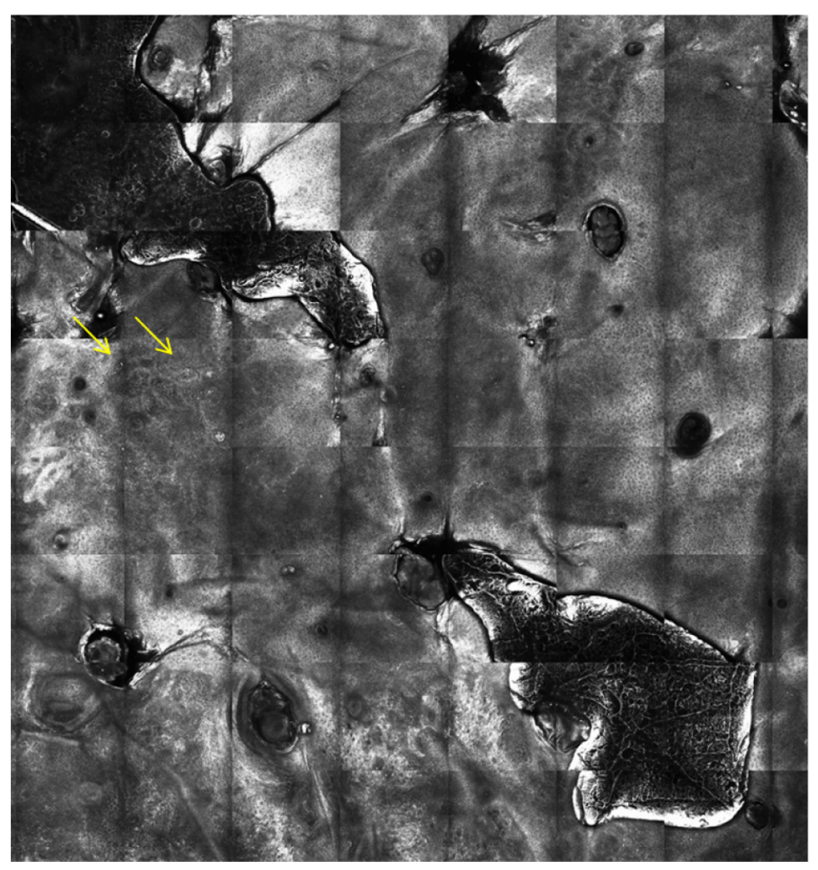

arrows). B Detail after treatment with complete recovering of honeycomb pattern and decrease in inflammatory cells (yellow arrows)

In the present randomized double-blind parallel-group study, subjects with grade III AK were treated once daily for 3 months with the medical device under study, showing a significant reduction in the number of $\mathrm{AK}$ lesions compared with placebo. Also, the total LSR scores were statistically reduced in subjects treated with the medical device after 3 months of treatment and follow-up (further 3 months). Complete clearance of lesions was observed during the first 3 months after the treatment period (i.e., the follow-up period) in $56.7 \%$ of the subjects treated with the medical device, and complete clearance achieved in $27.5 \%$ of subjects during the first 3 months after the treatment period (i.e., the follow-up period).

The medical device evaluated in this study, containing urea and 2,4,6-octatrienoic acid, could have the advantage of improving subject adherence, as also reported by the self-assessment questionnaire. Therefore, in our study, no serious adverse events were reported by all treated subjects. 
A

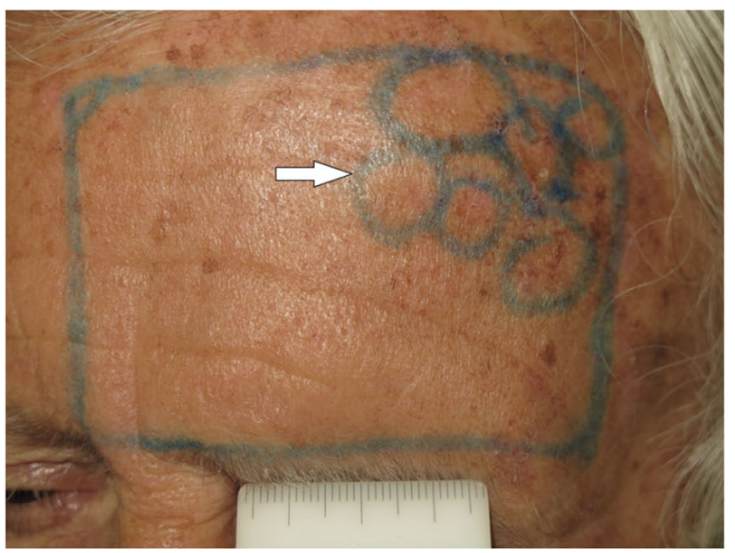

B

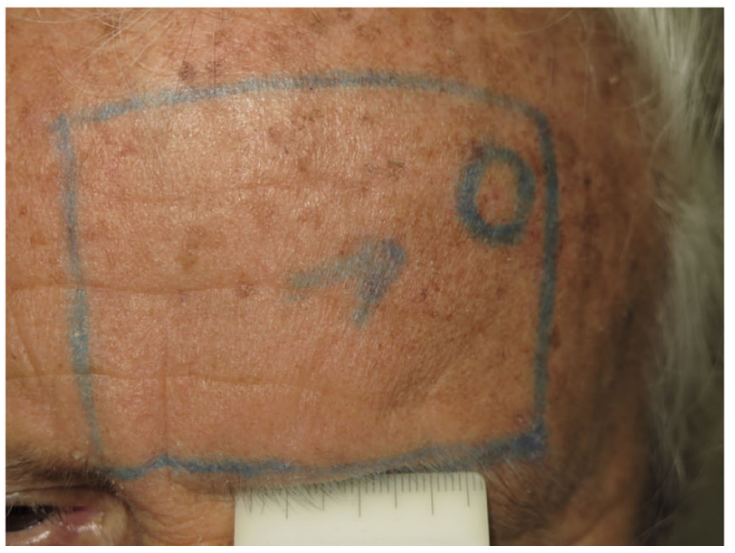

Fig. 3 Clinical images showing the treated area, at baseline (a), and after treatment (b)

Some study limitations should be taken into account in evaluating the study results. First, the diagnoses of AK were not confirmed histopathologically, but it has been reported that the clinical recognition by dermatologists has high diagnostic accuracy. Secondly, the study was not in the form of a comparative trial with other medications.

\section{CONCLUSION}

In conclusion, the studied medical device containing 2,4,6-octatrienoic acid and urea applied once daily for 90 consecutive days was found to be a safe and effective alternative treatment for grade III AK.
Its efficacy was evident till 3 months after the end of treatment.

\section{ACKNOWLEDGEMENTS}

We thank the participants of the study.

Funding. The study and article processing charges were funded by Giuliani SpA. All authors had full access to all of the data in this study and take complete responsibility for the integrity of the data and the accuracy of the data analysis.

Authorship. All named authors meet the International Committee of Medical Journal Editors (ICMJE) criteria for authorship for this manuscript, take responsibility for the integrity of the work as a whole, and have given final approval for the version to be published.

Author Contributions. All authors participated in study design, data collection, data interpretation, development, review, and final approval of the manuscript. G.B. and S.C. performed the assessor-blinded evaluation of coded pictures for the calculation and scoring of primary outcomes.

Compliance with Ethics Guidelines. This study was conducted in compliance with the ethical principles originating in or derived from the Declaration of Helsinki and in compliance with Good Clinical Practice Guidelines and was approved by the ethical committee of the University of Campania, Naples, Italy. All subjects provided signed informed consent.

Disclosures. F.R. and A.T. serve as a consultant for Giuliani S.p.A. D.P. is employed by Giuliani S.p.A. G.G. is on the board of directors of Giuliani S.p.A.

Data Availability. The datasets used and/or analyzed during the current study are available from the corresponding author on reasonable request. 
Open Access. This article is licensed under a Creative Commons Attribution-NonCommercial 4.0 International License, which permits any non-commercial use, sharing, adaptation, distribution and reproduction in any medium or format, as long as you give appropriate credit to the original author(s) and the source, provide a link to the Creative Commons licence, and indicate if changes were made. The images or other third party material in this article are included in the article's Creative Commons licence, unless indicated otherwise in a credit line to the material. If material is not included in the article's Creative Commons licence and your intended use is not permitted by statutory regulation or exceeds the permitted use, you will need to obtain permission directly from the copyright holder. To view a copy of this licence, visit http://creativecommons.org/licenses/by$\mathrm{nc} / 4.0 /$.

\section{REFERENCES}

1. Massone C, Cerroni L. The many clinico-pathologic faces of actinic keratosis: an atlas. Curr Probl Dermatol. 2015;46:64-9.

2. Filosa A, Filosa G. Actinic keratosis and squamous cell carcinoma: clinical and pathological features. G Ital Dermatol Venereol. 2015;150(4):379-84.

3. Roewert-Huber J, Stockfleth E, Kerl H. Pathology and pathobiology of actinic (solar) keratosis-an update. Br J Dermatol. 2007;157(Suppl 2):18-20.

4. Schwartz RA, Bridges TM, Butani AK, Ehrlich A. Actinic keratosis: an occupational and environmental disorder. J Eur Acad Dermatol Venereol. 2008;22(5):606-15.

5. Salasche SJ. Epidemiology of actinic keratoses and squamous cell carcinoma. J Am Acad Dermatol. 2000;42(1 Pt 2):4-7.

6. Anwar J, Wrone DA, Kimyai-Asadi A, Alam M. The development of actinic keratosis into invasive squamous cell carcinoma: evidence and evolving classification schemes. Clin Dermatol. 2004;22(3): 189-96.

7. Huang A, Nguyen JK, Austin E, Mamalis A, Jagdeo J. Updates on treatment approaches for cutaneous field cancerization. Curr Dermatol Rep. 2019;8(3): 122-32.
8. Slaughter DP, Southwick HW, Smejkal W. Field cancerization in oral stratified squamous epithelium. Clinical implications of multicentric origin. Cancer. 1953;6(5):963-8.

9. Rongioletti F. Actinic keratoses: what classification is useful to predict the risk of progression? PROs and cons. J Eur Acad Dermatol Venereol. 2019;33(6):983-4.

10. Cantisani C, Paolino G, Melis M, Faina V, Romaniello F, Didona D, Cardone M, Calvieri S. Actinic keratosis pathogenesis update and new patents. Recent Pat Inflamm Allergy Drug Discov. 2016;10(1):40-8.

11. Jans J, Garinis GA, Schul W, et al. Differential role of basal keratinocytes in UV-induced immunosuppression and skin cancer. Mol Cell Biol. 2006;26(22):8515-26.

12. Mittelbronn MA, Mullins DL, Ramos-Caro FA, Flowers FP. Frequency of pre-existing actinic keratosis in cutaneous squamous cell carcinoma. Int J Dermatol. 1998;37(9):677-81.

13. Fuchs A, Marmur E. The kinetics of skin cancer: progression of actinic keratosis to squamous cell carcinoma. Dermatol Surg. 2007;33(9):1099-101.

14. Dodds A, Chia A, Shumack S. Actinic keratosis: rationale and management. Dermatol Ther (Heidelb). 2014;4(1):11-31.

15. Puig S, Granger C, Garre A, Trullàs C, Sanmartin O, Argenziano G. Review of clinical evidence over 10 years on prevention and treatment of a film-forming medical device containing photolyase in the management of field cancerization in actinic keratosis. Dermatol Ther (Heidelb). 2019;9(2):259-70.

16. Dianzani C, Conforti C, Giuffrida R, Corneli P, di Meo N, Farinazzo E, Moret A, Magaton Rizzi G, Zalaudek I. Current therapies for actinic keratosis. Int J Dermatol. 2020;59(6):677-84.

17. Pan M, Heinecke G, Bernardo S, Tsui C, Levitt J. Urea: a comprehensive review of the clinical literature. Dermatol Online J. 2013;19(11). https:// escholarship.org/uc/item/11x463rp.

18. Flori E, Mastrofrancesco A, Kovacs D, Ramot $\mathrm{Y}$, Briganti S, Bellei B, Paus R, Picardo M. 2,4,6-Octatrienoic acid is a novel promoter of melanogenesis and antioxidant defence in normal human melanocytes via PPAR- $\gamma$ activation. Pigment Cell Melanoma Res. 2011;24(4):618-30.

19. Flori E, Mastrofrancesco A, Kovacs D, Bellei B, Briganti S, Maresca V, Cardinali G, Picardo M. The activation of PPAR $\gamma$ by 2,4,6-octatrienoic acid 
protects human keratinocytes from UVR-induced damages. Sci Rep. 2017;7(1):9241.

20. Heppt MV, Leiter U, Steeb T, Amaral T, Bauer A, Becker JC, et al. S3 guideline for actinic keratosis and cutaneous squamous cell carcinoma-short version, part 1: diagnosis, interventions for actinic keratoses, care structures and quality-of-care indicators. J Dtsch Dermatol Ges. 2020;18(3):275-94.

21. Rosen T, Lebwohl MG. Prevalence and awareness of actinic keratosis: barriers and opportunities. J Am Acad Dermatol. 2013;68:S2-9.

22. Tan JM, Sinnya S, Soyer HP. The ratio of non-hyperkeratotic and hyperkeratotic actinic keratosis in a high-risk non-melanoma skin cancer cohort in Queensland. J Eur Acad Dermatol Venereol. 2016;30(3):473-4.

23. Dréno B, Amici JM, Basset-Seguin N, Cribier B, Claudel JP, Richard MA; AKTeam ${ }^{\mathrm{TM}}$. Management of actinic keratosis: a practical report and treatment algorithm from AKTeam ${ }^{\mathrm{TM}}$ expert clinicians. J Eur Acad Dermatol Venereol. 2014;28(9):1141-9.

24. Richard MA, Amici JM, Basset-Seguin N, Claudel JP, Cribier B, Dreno B. Management of actinic keratosis at specific body sites in patients at high risk of carcinoma lesions: expert consensus from the AKTeamTM of expert clinicians. J Eur Acad Dermatol Venereol. 2018;32(3):339-46.
25. Herranz P, Morton C, Dirschka T, Azeredo RR, Roldán-Marín R. Low-dose 0.5\% 5-fluorouracil/10\% salicylic acid topical solution in the treatment of actinic keratoses. J Cutan Med Surg. 2016;20(6): 555-61.

26. Topical imiquimod therapy for actinic keratosis: is long-term clearance a realistic benefit?. J Clin Aesthet Dermatol. 2008;1(3):44-7.

27. Lombardi M, Rossi A, Fortuna MC, Garelli V, Sama E, Senis D, Costa C. Treatment of facial actinic keratoses with a cream containing octatrienoic acid: a multi center clinical experience. G Ital Dermatol Venereol. 2018;153(6):860-5.

28. De Padova MP, Marzani B, Pinto D, Rinaldi F. A single-arm, open-label, phase IV study to evaluate the efficacy of a topical formulation for hyperkeratotic actinic keratosis lesions. Dermatol Ther (Heidelb). 2018;8(3):455-62.

29. Morelli R, Loscalzo R, Stradi R, Bertelli A, Falchi M. Evaluation of the antioxidant activity of new carotenoid-like compounds by electron paramagnetic resonance. Drugs Exp Clin Res. 2003;29(3):95-100.

30. Pini E, Bertelli A, Stradi R, Falchi M. Biological activity of parrodienes, a new class of polyunsaturated linear aldehydes similar to carotenoids. Drugs Exp Clin Res. 2004;30(5-6):203-6. 